\title{
Peter Zweifel, Friedrich Breyer, Mathias Kifmann: Health Economics
}

\author{
Springer, 2009, 529 pp, hardcover; ISBN: 978-3-540-27804-7
}

\section{Simone Torka}

Published online: 25 May 2010

(C) Springer-Verlag 2010

The second edition of Health Economics is based on the German version of 1992. It contains all important facts on the specific characteristics of health products and global health markets at an advanced economic level. Additionally the authors describe current studies, e.g. that the consumption of medicine to control hypertension could undergo the influence of a strict diet and therefore could shorten the lifetime of patients with hypertension when they substitute a diet for medicine. These studies show clear results, not only for students of public health. The detailed mathematical formulas and derivation of theories are helpful for a better understanding of methodology but not implicitly necessary for an understanding of the chains of cause and effect. Each chapter concludes with a summary and exercise questions which turn it into a valuable workbook.

For a short impression have a look at the contents:

- Introduction

- Economic valuation of life and health
- Empirical studies of the production of health

- Health goods, market failure and justice

- Optimal health insurance contracts

- Risk selection in health insurance markets

- Physicians as suppliers of medical services

- Hospital services and efficiency

- Paying providers

- Forms of delivery of medical care

- The market for pharmaceuticals

- The political economy of health care

- Future challenges to health care systems

The basic chapters of Health Economics are well examined and approved. Recent research and current problems of health policies turn this comprehensive overview into a valuable work of reference for experts as well. 